\title{
Identifying the Factors Affecting Prioritization of Granting Facilities to Bank Customers and Ranking them Using VIKOR Rough Method (Case Study: Tejarat Bank)
}

\author{
Mohammad Reza Shahraki ${ }^{1}$, Abolfazl Bameri ${ }^{2 *}$ \\ ${ }^{1}$ Ph.D. in Industrial Engineering, Faculty member of Sistan and Baluchestan University, Iran \\ m.reza.shahraki@eng.usb.ac.ir \\ $2^{2 *}$ Master Student of Industrial Engineering, University of Sistan and Baluchestan, Iran \\ abolfazlbameri@pgs.usb.ac.ir
}

\begin{abstract}
Banks should optimally allocate their financial resources to qualified customers. Optimal allocation of financial resources provides the conditions for the banks' economic activity continuation. To grant facilities to customers, the factors affecting the granting facilities to banks' customers need to be properly identified. In this study, Delphi method was used to identify the factors affecting granting facilities to banks' customers. Then, using the VIKOR Rough Theory, these customers were prioritized aimed at granting facilities to them. The results showed that the factors of location of the facilities granted and the type of the facilities use (use of received facilities in the subject of the regulated contract), history of activity, value of customer capital, type of collateral, having previous liabilities, good reputation of the applicant, and estimated return on capital, respectively, were identified as the most important factors in granting facilities. Finally, the customers were ranked by VIKOR Rough method to receive the banking facilities.
\end{abstract}

Keywords: Identification, Ranking, Granting facilities, Rough Set Theory, VIKOR

\section{Introduction}

In the process of granting facilities, decision making is considered as the most important activity of financial organizations. Selecting a safe and low-risk project for investment is one of the important factors in the success of banks in resources allocation (Zabihi et al., 2012). Given variable economic conditions and lack of paying attention to some of the factors that influence the success of a project, selection of a project faces problems. Moreover, payment of facilities involves a long time procedure with the possibility of error and mistake (Naghadeh et al., 2013).

Zabihi et al. (2012) investigated the issue of identifying and prioritizing the loan granting criteria using the fuzzy hierarchy process. The aim of their study was to identify and prioritize the indicators and rankings of banks from the viewpoint of experts and managers of three banks, including Melli, Mellat and Refah-e Kargaran, as well as banking experts in Shiraz. The criteria identified by them were the applicant's qualifications, technical feasibility, organization characteristics and financial analysis. They also identified sub-criteria of each of the main criteria, and prioritized each criterion and sub-criterion using the Cheng and Mon Distance Method, and finally ranked the banks. In another study, Naghadeh et al. (2013) presented a methodology for selecting the preferred person for granting the facilities. They proposed a fuzzy VIKOR method to select the preferred person for the granting of facilities

As a wide variety of research has been conducted on granting of facilities for customers with use of various methods and as granting of facilities is considered as one of the most important activities of the banking system, the main issue in this research is to identify the factors affecting the granting of facilities for customers by using Delphi method and ranking of customers of Tejarat Bank of Zabol to grant facilities with use of Rough VIKOR method. In the second section of this research, research literature on granting of facilities to bank customers is reviewed. In the third section, the research method based on the Rough VIKOR method is presented. In the fourth section, based on a case study conducted in Tejarat Bank of Zabol, the results are analyzed. In the fifth section, we summarize and conclude the results, and finally provide some recommendations for future research to improve the quality of banking services. 


\section{Review of Literature}

Assessing and granting of facilities is a theoretical subject and its non-quantitative nature makes it difficult to accurately measure and prove it in credit decisions. Credit decisions, like all techniques, the basic criteria provided by experts are used. These criteria are not fixed scientific rules and are the product of human thought and theory and subject to change (Shahgholian et al., 2011). Applying these criteria ensures the return of the allocated resources and expected profits within a given period. Considering each of the credit criteria individually is not a reliable base for taking credit decisions, but a set of criteria that can provide a reliable basis for making decisions needs to be considered. Additionally, granting of facilities requires sufficient skill and experience. To achieve the principle of resources return, accuracy and precision based on the necessary criteria is needed when granting facilities. Non-organized rules for granting facilities pave the way for the approval of projects that are not qualified. Research suggests that criteria needed for granting vary across countries. Table 1 summarizes the criteria in the three countries of Australia, Japan and Norway (Aghaei, 2009).

Table 1: The criteria for granting facilities in Japan, Australia and Norway (Aghaei, 2009)

\begin{tabular}{|c|l|}
\hline country & \multicolumn{1}{|c|}{ criteria } \\
\hline \multirow{5}{*}{ Japan } & $\begin{array}{l}\text { 1. Technical feasibility analysis of the project } \\
\text { 2. Examining the qualification of the borrower (institution or person) } \\
\text { 3. Commercial analysis of the project } \\
\text { 4. Financial and economic analysis of the project }\end{array}$ \\
\hline \multirow{5}{*}{ Australia } & $\begin{array}{l}\text { 1. The financial ability of the borrower in repaying the loan } \\
\text { 2. Borrower's power (loan to capital ratio) }\end{array}$ \\
& $\begin{array}{l}\text { 4. The level of support from borrower } \\
\text { 5- Characteristics and background of the borrower }\end{array}$ \\
& $\begin{array}{l}\text { 1. Personality } \\
\text { 2. Experience } \\
\text { 3. Specifications of manufactured goods } \\
\text { 4. Market conditions and specifications } \\
\text { 5. Organization Characteristics } \\
\text { 6. Financial aspects }\end{array}$ \\
\hline
\end{tabular}

Banking facilities are the main outputs of banks through which the wandering liquidity of society is injected into defined and purposeful economic bases. It means that a bank with equipment of resources (including equity and types of deposits or other liabilities) consumes them for pre-specified purposes (Amiri \& Amiri, 2015). In other words, it is assumed that a bank will make a profit by creating these revenue-generating assets at the end of each financial period and expand its business by accumulated profits and new resources, including increasing capital or creating other liabilities. However, in developmental banks, which are usually set up by government capitals, achieving national and economic goals is more important than bank profitability (Amiri \& Amiri, 2015). Rough set theory was developed in the 1980s by Pawlak. This theory states and examines the issues in which there is uncertainty and ambiguity. It is commonly used to find inconsistencies and relationships (Pawlak et al., 2003). The most important characteristics of this theory are:

- Optimized algorithm for finding patterns in data.

- Finding relationships that are not discovered by statistical methods.

- Ability of using qualitative and quantitative information.

- Finding a minimal set of data that are useful for classification (such as minimizing dimensions and number of information).

- Assessing the importance of data.

Generating decision-making rules from information (Pawlak et al., 2003)

VIKOR is a Serbian abbreviation of Vlse Kriterijumsk Optimizacija Kompromisno Resenje which is one of the most widely used models in decision making and selecting top option. This model has been developed since 1984 on the basis of a collective agreement (consensus) method with conflicting criteria and is generally used to solve discrete problems. This method has been developed for multi-criteria optimization of complex systems. This method focuses on the classification and selection of a set of options and identifies adaptive responses to a problem with conflicting criteria so that it is able to help decision makers achieve a final decision. Here, the adaptive answer is the nearest justified answer to the ideal answer (Asgharpour, 2011). Khamse et al. (2007) developed an expert system to grant loans to customers. Their expert system is based on quantitative and qualitative factors. Che et al. (2010) in Taiwan presented a DEA-FAHP approach for making decision on bank 
loans. They evaluated the performance of companies by FAHP method. The weight of criteria and data of companies were obtained using fuzzy hierarchy method. To evaluate performance, DEA method was used. Performance scores led to the identification of the final candidates for bank loans. Shahgholian et al. (2011) presented a decision model for granting banking facilities using fuzzy method. This model is based on the decision table and the if-then rules called as control rules.

Hsiao et al. (2011) used a shortage-based measurement approach in Taiwan to analyze the performance of 24 commercial banks facing loan and investment problems using fuzzy data envelopment analysis. Odeh et al. (2011) proposed a multi-objective approach to predict loan defaults. They used the Simplex Fuzzy Genetic Algorithm (a multi-objective optimization algorithm) to create decision rules to predict loan defaults. The results showed that the best indicators of the default situation are observed when the capacity of re-payment and equity is low and overhead capital is low or high. Moreover, the worst risk indicators include low repayment capacity, high equity, moderate capital or moderate repayment capacity, and low equity. Zabihi et al. (2012) identified and prioritized granting loan criteria using fuzzy hierarchy technique. It was conducted on three banks of Melli, Mellat, and Refah-e Kargaran. The applicant's qualifications, technical feasibility, organization specifications and financial analysis were identified. Da Silva and Divino (2013) evaluated the role of credit risk and liquidity shock in banks. This article develops a dynamic correction general equilibrium model that includes a financial sector to analyze the effects of liquidity shock and credit risk on the Brazilian economy. Using data for the Brazilian economy from 1995 to 2009, the parameters of this structure were measured through Bayesian methods. Impulse response distribution has been calculated to describe the dynamic effects of external shocks. The results showed that the credit risk is almost the same and the default risk depends on the structural characteristics.

Kighobadi and Khodami (2013) used data mining of financial statements for granting facilities. The way of making decisions about granting facilities for customers is important since lack of accurate evaluation of customers can lead to past maturity and delayed debt, reduced banks capacity to grant facilities, and finally bad debts. This study was conducted to model the validation of customers in the bank using neural network, decision tree and support-vector machine methods. For this purpose, financial and qualitative data were collected from a random sample of 300 customers (218 creditworthy customers and 82 non-creditworthy customers) received credit facilities from legal companies in Melli Bank branches of Tehran. In this research, after reviewing the credit records of the customers, 31 explanatory variables were evaluated and the results showed that data mining techniques are highly efficient for customer validation and neural network model prediction performance is better than other models.

Castro (2013) evaluated the macroeconomic factors in credit risk in the banking system. In this paper, the relationship between economic progress and the risks of bank facilities in a specific group of countries (Greece, Ireland, Portugal, Spain and Italy) affected by adverse economic and financial conditions was analyzed. Using dynamic data approaches, it was concluded that bank credit risk is significantly affected by the macroeconomic environment. The results showed that when gross domestic products (GDP) growth and the stock and housing price index change, unemployment rate, interest rate and credit growth will be also positively affected by a concept of real exchange rate. Imbierowicz and Rauch (2014) evaluated the relationship between liquidity risk and credit risk in banks. They evaluated the relationship between two main sources of bank risk default, including liquidity risk and credit risk. They used a sample of almost all US commercial banks in the period 1998-2010 to evaluate the relationship between these two sources of risk. The results revealed that none of risk groups have significant inverse economic relationship. However, they do affect the probability of banks' predictions. Both risks increase banks' probabilities separately, the effect of their interaction depends on the general level of banking risk and can exacerbate or reduce the risk of default.

Karimi et al. (2015) examined the factors affecting the credit risk of commercial bank customers. This article evaluates the factors affecting the banks' delayed loans and credit risk of real customers of Tejarat Bank branches of Neka. The data needed to analyze this relationship were extracted from 2,545 real customer records received during 2011 to 2002 and logistic regression was used to evaluate the data. The results of this research revealed that the duration of the facilities, the rate of the facilities, the type of collateral and the type of facilities have a significant effect on the receivables and the obligatory or no-obligatory nature of facilities and the rate of facilities had no significant effect on the probability of default. The probability of non-repayment increases with reducing repayment period and increasing facilities rates. Moreover, with regard to the types of collateral for granting loan, the greatest effect in reducing the probability of non-repayment is related to the bank deposit and the least effect is related to promissory note. In addition, the greatest effect on increasing the possibility of non-repayment is related to loan facilities and the least effect is related to participation facilities.

Manab et al. (2015) investigated the factors affecting credit risk in Malaysia. The aim of this study was to investigate the factors determining the credit risk and to evaluate the effect of earnings management on credit risk prediction. The results revealed that the liquidity ratio in determining credit risk was moderated before and after earnings management. Moreover, the productivity ratio in the non-moderated model was significant; while, the profitability ratio in the moderated model was significant. Amiri and Amiri (2015) performed technical and 
economical evaluation of loan applications using fuzzy analytic network technique. In this study, effective criteria in evaluating loan applicant projects were identified and analyzed and a model was presented to evaluate the projects. In the evaluation section, using the survey form, the pairwise comparisons matrix, and the fuzzy metric network analysis method, the criteria weights were determined and by determining the value of each criterion, the result of each criterion was obtained. Turan (2016) evaluated the factors affecting credit in banking. Banks face the problems of the payment of loans that is a serious risk for them. Hence, banks effectively manage risk. Credit risk is more commonly recognized as the potential risk that a bank granting the facilities will not be able to meet its repayment in accordance with the agreed terms. The banks that manage risk effectively evaluate their risks in details.

The banks must use the efficiency of external funds since banking activities are determined by external budgets. Banks give credit to their customers to receive their funds. Banks are also exposed to credit risk. Credit risk is close to the potential return on capital. The results of the studies showed that credit risk is the most important risk for banks. Hierarchy analysis as one of the multiple criterion decision making techniques is used in the evaluation of these criteria. At the end of the study, the weights of the factors affecting credit risk were found. Ghenimi et al. (2017) investigated the effects of liquidity risk and credit risk on bank stability. The global financial crisis has caused a series of bank failures. This study investigates the main sources of bank fragility. This study used a sample of 49 banks in the MENA region during 2006-2012 to investigate the relationship between credit risk and liquidity risk and its effect on bank stability. The results revealed that credit risk and liquidity risk were not inversely associated with remaining time. However, both risks affect the stability of the bank separately and their interaction causes bank instability.

\section{Methodology}

The current research is applied in terms of objective. It is an applied study as it uses scientific rules and principles and seeks to solve a problem on the one hand (Khaki, 2008) and identify the factors affecting the granting of facilities and the ranking of the customers for the granting of facilities on the other hand. It is also considered a field study in terms of method.

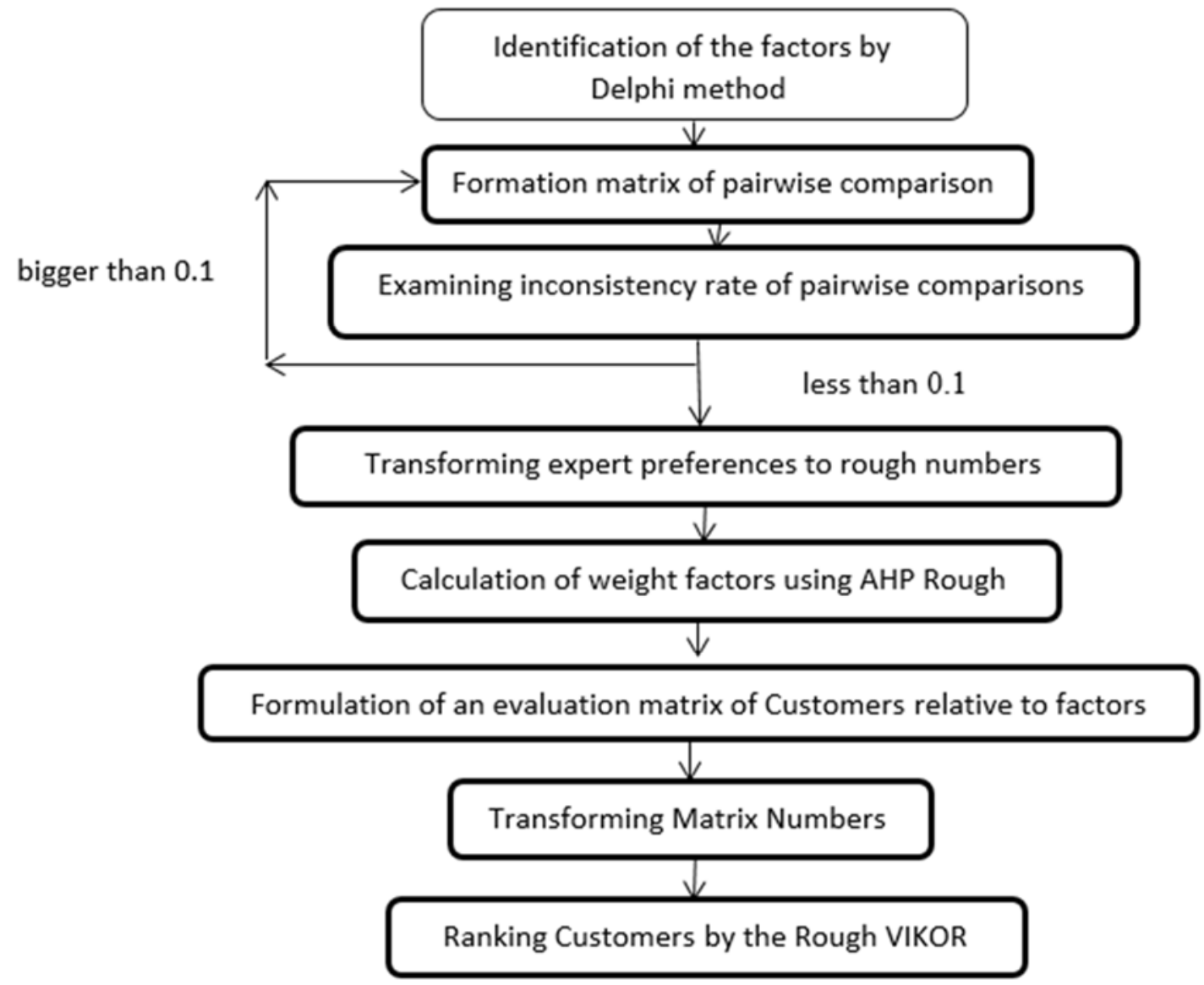

Figure 1- The steps of the research 
In this paper, the previous data and the Delphi method are used to identify the key and effective factors in granting facilities for bank customers. In the first step, the most frequent factors are selected from previous studies and the important factors are identified based on bank experts' opinions. Then, using the Delphi method, the most important factors affecting the granting of facilities will be identified among all the factors.

In the Delphi method, in order to identify the factors affecting the granting facilities to customers by banks, a checklist of these factors is extracted from previous studies and classified using experts' opinions. A list of factors is provided to the banking experts through a questionnaire and they are asked to identify the key and important factors affecting the granting of facilities to banks' customers. In this step, only the selection of key factors is considered. By collecting questionnaires and summarizing the experts' opinions in three rounds, the key factors are finally selected. Then, using the pairwise comparisons questionnaire, the experts' opinions are collected for pairwise comparison of factors and the opinions are pooled and finally the effective weight of each factor affecting granting of the facilities for customers is obtained.

In this step of the research, the customers who have received bank facilities in the past will be ranked using the identified factors and their effective weights and Rough VIKOR method to demonstrate the effectiveness of this method.

\section{3-1- AHP Rough steps for factors weighting}

AHP is widely used as one of the most popular methods in various decision-making issues, especially in weighting of factors. AHP can measure preferences' consistency, control tangible and intangible criteria, and manage decisions about subjective judgments. Given the uncertainty and ambiguity of decision-making, this research introduces the Rough number to combine with the AHP to collect individual judgments and calculate the relative importance of each factor. The AHP Rough method is described below (Zhu et al., 2015).

Step 1: Matrix of $\mathrm{K}^{\text {th }}$ paired comparisons is defined as matrix (1)

$$
\mathrm{B}_{\mathrm{k}}=\left[\begin{array}{cccc}
1 & \mathrm{r}_{12}^{\mathrm{k}} & \ldots & \mathrm{r}_{1 \mathrm{n}}^{\mathrm{k}} \\
\mathrm{r}_{21}^{\mathrm{k}} & 1 & \ldots & \mathrm{r}_{2 \mathrm{n}}^{\mathrm{k}} \\
\vdots & \vdots & \ddots & \vdots \\
\mathrm{r}_{\mathrm{n} 1}^{\mathrm{k}} & \mathrm{r}_{\mathrm{n} 2}^{\mathrm{k}} & \ldots & 1
\end{array}\right] \quad \mathrm{k}=1.2, \ldots, \mathrm{m}
$$

So that $r_{i j}^{k}$ is the $\mathrm{k}^{\text {th }}$ expert judgment for comparing factor $\mathrm{i}$ with factor $\mathrm{j} . \mathrm{m}$ is the number of experts and $\mathrm{n}$ is the number of factors.

Step 2: The pairwise comparisons of the experts are examined in terms of inconsistency rate by Expert Choice software and if the inconsistency rate is less than 0.1 , the pairwise comparison is consistent, and if it is greater than 0.1 , the pairwise comparison numbers should be corrected.

Step 3: In this section, to combine the personal judgment of the experts, the geometric mean method is proposed as relation (2), since it retains the inverse feature of the pairwise comparative matrices without violating Pareto principles (Forman \& Peniwati, 1998).

$$
\begin{gathered}
r_{i j}=\left(\prod_{k=1}^{m} r_{i j}^{k}\right)^{\frac{1}{m}} \\
r_{i j}=\left(\prod_{k=1}^{m} r_{i j}^{k}\right)^{\frac{1}{m}}
\end{gathered}
$$

Thus, $\mathrm{M}$ rough pairwise comparison is formed as follows:

$$
M=\left[\begin{array}{cccc}
\lceil 1,1\rfloor & \left\lceil x_{12}^{L}, x_{12}^{U}\right\rfloor & \cdots & \left\lceil x_{1 m}^{L}, x_{1 m}^{U}\right\rfloor \\
\left\lceil x_{21}^{L}, x_{21}^{U}\right\rfloor & \lceil 1,1\rfloor & \cdots & \left\lceil x_{2 m}^{L}, x_{2 m}^{U}\right\rfloor \\
\vdots & \vdots & \ddots & \vdots \\
\left\lceil x_{m 1}^{L}, x_{m 1}^{U}\right\rfloor & \left\lceil x_{m 2}^{L}, x_{m 2}^{U}\right\rfloor & \cdots & \lceil 1,1\rfloor
\end{array}\right]
$$

Step 4: Calculating the interval weight of each factor using the following equations:

$$
W_{g}=\left\lceil\sqrt[m]{\prod_{h=1}^{m} x_{g h}^{L}}, \sqrt[m]{\prod_{h=1}^{m} x_{g h}^{U}}\right\rfloor
$$

$\mathrm{W}_{\mathrm{g}}^{\prime}$ is the normal weight of each factor. 


$$
W_{g}^{\prime}=\frac{W_{g}}{\max \left(W_{g}^{U}\right)}
$$

\section{3-2- The steps of the Rough VIKOR Method}

The assumptions and steps of the proposed method are as follows (Sayadi et al., 2009)

\section{The method's assumptions:}

There are $\mathrm{K}$ decision makers whose opinions are equally important in the final decision $(\mathrm{k}=1,2, \ldots, \mathrm{K})$

There are $\mathrm{m}$ options for selecting $(\mathrm{i}=1,2, \ldots, \mathrm{m})$

There are $\mathrm{n}$ factors $/$ indicators for decision making $(\mathrm{j}=1,2, \ldots, \mathrm{n})$

\section{The method steps:}

The first step is to form an individual decision matrix using the opinions of bank experts. In matrix (1), the rows indicate the options that are the past customers received the facilities and the columns are the status of key factors in granting facilities to customers.

$$
F_{i j}^{k}=\left(\begin{array}{cccc}
f_{11}^{k} & f_{12}^{k} & \ldots & f_{1 n}^{k} \\
f_{21}^{k} & f_{22}^{k} & \ldots & f_{2 n}^{k} \\
\vdots & \vdots & \ddots & \vdots \\
f_{m 1}^{k} & f_{m 2}^{k} & \ldots & f_{m n}^{k}
\end{array}\right)
$$

Where $f_{i j}^{k}$ is the function of option $\mathrm{i}$ in relation to the criterion $\mathrm{j}$ for the expert $\mathrm{k}$. Then, the group decision matrix is formed as matrix (7).

$$
F=\left(\begin{array}{cccc}
f_{11} & f_{12} & \ldots & f_{1 n} \\
f_{21} & f_{22} & \ldots & f_{2 n} \\
\vdots & \vdots & \ddots & \vdots \\
f_{m 1} & f_{m 2} & \ldots & f_{m n}
\end{array}\right)
$$

Where,

$$
f_{i j}=\left\{f_{i j}^{1}, f_{i j}^{2}, \ldots, f_{i j}^{k}, \ldots, f_{i j}^{m}\right\}
$$

Step 2: Transforming component $f_{i j}$ in the matrix $\mathrm{F}$ to the Rough number to form the $\mathrm{F}$ Rough group evaluation matrix using equations (9) and (10).

$$
\begin{array}{ll}
\underline{\operatorname{Apr}}\left(r_{i j}^{k}\right)=\cup\left\{Y \in U / R(Y) \leq r_{i j}^{k}\right\} & ) 9( \\
\overline{\operatorname{Apr}}\left(r_{i j}^{k}\right)=\cup\left\{Y \in U / R(Y) \geq r_{i j}^{k}\right\} & ) 10(
\end{array}
$$

Thus, $f_{i j}^{k}$ can be shown as a Rough number defined by its lower $\operatorname{limit} \underline{\operatorname{Lim}}\left(f_{i j}^{k}\right)$ and upper limit $\overline{\operatorname{Lim}}\left(f_{i j}^{k}\right)$ as equations 11 and 12:

$$
\begin{aligned}
& \underline{\operatorname{Lim}}\left(f_{i j}^{k}\right)=\left(\prod_{m=1}^{N_{i j L}} x_{i j}\right)^{\frac{1}{N_{i j L}}} \\
& \overline{\operatorname{Lim}}\left(f_{i j}^{k}\right)=\left(\prod_{m=1}^{N_{i j U}} y_{i j}\right)^{\frac{1}{N_{i j U}}}
\end{aligned}
$$

$x_{i j}$ and yij are the low approximation and high approximation components for $f_{i j}^{k} \mathrm{k} . N_{i j L}$ and $N_{i j U}$ are the number of components that fall into the low approximation and the high approximation of $f_{i j}^{k}$, respectively. The $\mathrm{RN}\left(f_{i j}^{k}\right)$ can be determined by the following equation (13).

$$
R N\left(f_{i j}^{k}\right)=\left[\underline{\operatorname{Lim}}\left(f_{i j}^{k}\right), \overline{\operatorname{Lim}}\left(f_{i j}^{k}\right)\right]=\left[f_{i j}^{k L}, f_{i j}^{k U}\right]
$$

Where $f_{i j}^{k L}$ and $f_{i j}^{k U}$ are the lower limit and the upper limit of the $\mathrm{RN}\left(f_{i j}^{k}\right)$ in the decision matrix k. Therefore, a set of rough numbers in the form of a relation (14) can be formed.

$$
R N\left(f_{i j}\right)=\left\{\left[f_{i j}^{1 L}, f_{i j}^{1 U}\right],\left[f_{i j}^{2 L}, f_{i j}^{2 U}\right], \ldots,\left[f_{i j}^{m L}, f_{i j}^{m U}\right]\right\}
$$

Thus, the mean Rough distance can be obtained using the equations (15), (16), and (17).

$$
\overline{R N\left(f_{i j}\right)}=\left[f_{i j}^{L}, f_{i j}^{U}\right]
$$




$$
\begin{aligned}
& f_{i j}^{L}=\left(\prod_{k=1}^{m} f_{i j}^{k L}\right)^{\frac{1}{m}} \\
& f_{i j}^{U}=\left(\prod_{k=1}^{m} f_{i j}^{k U}\right)^{\frac{1}{m}}
\end{aligned}
$$

$f_{i j}^{L}$ and $f_{i j}^{U}$ are the lower limit and upper limit of the Rough number $\left[f_{i j}^{L}, f_{i j}^{U}\right]$, respectively, and $\mathrm{m}$ is the number of experts. Then, we can form the F Rough group decision matrix as matrix (18).

$$
F=\left(\begin{array}{cccc}
{\left[f_{11}^{L}, f_{11}^{U}\right]} & {\left[f_{12}^{L}, f_{12}^{U}\right]} & \ldots & {\left[f_{1 n}^{L}, f_{1 n}^{U}\right]} \\
{\left[f_{21}^{L}, f_{21}^{U}\right]} & {\left[f_{22}^{L}, f_{22}^{U}\right]} & \ldots & {\left[f_{2 n}^{L}, f_{2 n}^{U}\right]} \\
\vdots & \vdots & \ddots & \vdots \\
{\left[f_{m 1}^{L}, f_{m 1}^{U}\right]} & {\left[f_{m 2}^{L}, f_{m 2}^{U}\right]} & \ldots & {\left[f_{m n}^{L}, f_{m n}^{U}\right]}
\end{array}\right)
$$

Step 3: Ideal positive $f_{j}^{*}$ and negative $f_{j}^{-}$options are determined using the rules of relations (19) to (20). If $\mathrm{j}$ criterion is a profit type, the ideal positive and negative values will be in the form of equations (19) and (20).

$$
\begin{aligned}
& f_{j}^{*}=\max \left(f_{i j}^{U}\right) \\
& f_{j}^{-}=\min \left(f_{i j}^{L}\right)
\end{aligned}
$$

If the criterion is a loss type, the ideal positive and negative values will be in the form of equations (21) and (22).

$$
\begin{aligned}
& f_{j}^{*}=\min \left(f_{i j}^{L}\right) \\
& f_{j}^{-}=\max \left(f_{i j}^{U}\right)
\end{aligned}
$$

Step 4: In this step, the value of the utility index Si and the regret index Ri of the options are calculated using equations (23) to (26). It should be noted that the weight of the factors was determined in the identification step. In each formula, the first part of the formula corresponds to the profit type criteria and the second part corresponds to cost type criteria, that in the absence of any of them, the corresponding value would be zero.

$$
\begin{aligned}
& S_{i}^{L}=\sum_{j=1}^{n} w_{j}\left(\frac{f_{j}^{*}-f_{i j}^{U}}{f_{j}^{*}-f_{j}^{-}}\right)+\sum_{j=1}^{n} w_{j}\left(\frac{f_{i j}^{L}-f_{j}^{*}}{f_{j}^{-}-f_{j}^{*}}\right), i=1,2, \ldots, m \\
& S_{i}^{U}=\sum_{j=1}^{n} w_{j}\left(\frac{f_{j}^{*}-f_{i j}^{L}}{f_{j}^{*}-f_{j}^{-}}\right)+\sum_{j=1}^{n} w_{j}\left(\frac{f_{i j}^{U}-f_{j}^{*}}{f_{j}^{-}-f_{j}^{*}}\right), i=1,2, \ldots, m \\
& R_{i}^{L}=\max \left\{w_{j}\left(\frac{f_{j}^{*}-f_{i j}^{U}}{f_{j}^{*}-f_{j}^{-}}\right), w_{j}\left(\frac{f_{i j}^{L}-f_{j}^{*}}{f_{j}^{-}-f_{j}^{*}}\right)\right\}, i=1,2, \ldots, m \\
& R_{i}^{U}=\max \left\{w_{j}\left(\frac{f_{j}^{*}-f_{i j}^{L}}{f_{j}^{*}-f_{j}^{-}}\right), w_{j}\left(\frac{f_{i j}^{U}-f_{j}^{*}}{f_{j}^{-}-f_{j}^{*}}\right)\right\}, i=1,2, \ldots, m
\end{aligned}
$$

Step 5: The VIKOR Q index is calculated based on the equations (27) and (28). First, V that is a number between zero and one must be determined depending on the decision maker's opinion. $\mathrm{V}$ is a weight for the maximum group utility strategy, which is usually considered as 0.5 .

$$
\begin{aligned}
& Q_{i}^{L}=v\left(\frac{S_{i}^{L}-S^{*}}{S^{-}-S^{*}}\right)+(1-v)\left(\frac{R_{i}^{L}-R^{*}}{R^{-}-R^{*}}\right) \\
& Q_{i}^{U}=v\left(\frac{S_{i}^{U}-S^{*}}{S^{-}-S^{*}}\right)+(1-v)\left(\frac{R_{i}^{U}-R^{*}}{R^{-}-R^{*}}\right)
\end{aligned}
$$

So that

$$
\begin{aligned}
& S^{*}=\min S_{i}^{L} \\
& S^{-}=\max S_{i}^{U} \\
& R^{*}=\min R_{i}^{L} \\
& R^{-}=\max R_{i}^{U}
\end{aligned}
$$

Step 6: The descending ranking of options based on VIKOR Index value, utility value, and regret value (Huang et al., 2009).

Step 7: Selecting the best option, with the lowest Q, will be achieved if the following two conditions are met (Rao, 2012):

Condition 1 (The acceptance characteristics): 


$$
\sqrt{1.2\left[\left(Q^{U}\left(A_{b}\right)-Q^{U}\left(A_{a}\right)\right)^{2}+\left(Q^{L}\left(A_{b}\right)-Q^{L}\left(A_{a}\right)\right)^{2}\right]} \geq \frac{1}{m-1}
$$

So that $\mathrm{A}^{[2]}$ is the option ranked second based on the lowest $\mathrm{Q}$ value, $\mathrm{A}^{[1]}$ is the best option with the lowest $\mathrm{Q}$ value and $\mathrm{m}$ the number of options (Zhou \& Tian, 2008).

Second condition (The acceptance stability in decision making):

The option $\mathrm{A}^{[1]}$ must also have the best rank in Si or Ri or both. This solution is consistent throughout the decisionmaking process, which can be in three forms: "voting with majority rule" (when $v>0.5$ is needed) or "by consensus" ( $\mathrm{v}=0.5)$ or "by opposite vote" $(\mathrm{v}<0.5)$.

If one of the above conditions was not met, a set of compromise solutions is suggested as follows:

1-If only the second condition is not met, option $\mathrm{A}^{[1]}$ and $\mathrm{A}^{[2]}$ or

2-If the first condition is not met, option $\mathrm{A}^{[1]}, \mathrm{A}^{[2]}$ and ... and $\mathrm{A}^{[\mathrm{k}]}$. (Rao, 2012)

$\mathrm{A}^{[\mathrm{k}]}$ is an option in the position of $\mathrm{k}$ that equation $\sqrt{\frac{1}{2}\left[\left(Q^{U}\left(A_{k}\right)-Q^{U}\left(A_{a}\right)\right)^{2}+\left(Q^{L}\left(A_{k}\right)-Q^{L}\left(A_{a}\right)\right)^{2}\right]}<\frac{1}{k-1}$ is true for it.

\section{Data analysis}

In this research, the factors were identified through interviews with experts and questionnaire (Delphi method). The factors were identified in three stages using Delphi method. Based on past studies, research literature, interviews, and online completion of questionnaires by 32 experts and implementing the first round of Delphi, a total of 30 factors were identified. These factors are listed in Table (1).

Table 2: The factors affecting granting facilities by bank

\begin{tabular}{|c|c|c|c|}
\hline \multirow{2}{*}{ Row } & \multirow{2}{*}{ Factors } & \multicolumn{2}{|l|}{ Source of research } \\
\hline & & Researcher(s) & Year \\
\hline 1 & Having previous liabilities & Azadi Moghaddam Arani et al. & 2004 \\
\hline 2 & Respiration time & Zabihi et al. & 2012 \\
\hline 3 & Level of facilities & Karimi et al. & 2015 \\
\hline 4 & Customer capital level & Zabihi et al & 2012 \\
\hline \multirow{2}{*}{5} & \multirow{2}{*}{ History of activity } & Naghadeh et al. & 2013 \\
\hline & & Azadi Moghaddam Arani et al. & 2004 \\
\hline \multirow{2}{*}{6} & \multirow{2}{*}{ Ratio of current asset } & Zabihi et al. & 2012 \\
\hline & & Azadi Moghaddam Arani et al. & 2004 \\
\hline 7 & Period of inventory turnover per day & Azadi Moghaddam Arani et al. & 2004 \\
\hline 8 & Collecting the debts per day & Azadi Moghaddam Arani et al. & 2004 \\
\hline 9 & Ownership ratio & Amiri.Z; \& Amiri.M. & 2015 \\
\hline 10 & Debt ratio & Amiri.Z; \& Amiri.M. & 2015 \\
\hline \multirow{2}{*}{11} & \multirow{2}{*}{ Good reputation of the applicant } & Zabihi et al. & 2012 \\
\hline & & Amiri.Z; \& Amiri.M. & 2015 \\
\hline \multirow{2}{*}{12} & \multirow{2}{*}{ Liquidity ratio } & Amiri.Z; \& Amiri.M. & 2015 \\
\hline & & Azadi Moghaddam Arani et al. & 2004 \\
\hline 13 & Balance Sheet & Zabihi et al. & 2012 \\
\hline 14 & $\begin{array}{c}\text { Conditions and standards for granting } \\
\text { facilities }\end{array}$ & Azadi Moghaddam Arani et al. & 2004 \\
\hline 15 & Level of asset owned & Azadi Moghaddam Arani et al & 2004 \\
\hline 16 & Average of account turnover & Azadi Moghaddam Arani et al. & 2004 \\
\hline 17 & Current capital to total asset & Amiri.Z; \& Amiri.M. & 2015 \\
\hline 18 & Financial statements (profit and loss) & Azadi Moghaddam Arani et al. & 2004 \\
\hline 19 & Insurance of facilities & Azadi Moghaddam Arani et al. & 2004 \\
\hline 20 & Location for use of facilities & Azadi Moghaddam Arani et al. & 2004 \\
\hline 21 & $\begin{array}{l}\text { Needs assessment and feasibility } \\
\text { assessment of facilities }\end{array}$ & Amiri.Z; \& Amiri.M. & 2015 \\
\hline 22 & Duration of facilities & Karimi et al. & 2015 \\
\hline
\end{tabular}




\begin{tabular}{|c|c|c|c|}
\hline \multirow{2}{*}{23} & Type of collateral & Karimi et al. & 2015 \\
\cline { 3 - 4 } & & Amiri.Z; \& Amiri.M. & 2015 \\
\hline 24 & Obligatory or non-obligatory facilities & Karimi et al. & 2015 \\
\hline \multirow{2}{*}{25} & \multirow{2}{*}{ History of receiving other facilities } & Amiri.Z; \& Amiri.M. & 2015 \\
\cline { 3 - 4 } & & Azadi Moghaddam Arani et al. & 2004 \\
\hline \multirow{2}{*}{26} & Having justification project & Zabihi et al. & 2012 \\
\cline { 3 - 4 } & & Nagadeh et al. & 2013 \\
\cline { 3 - 4 } & & Amiri.Z; \& Amiri.M. & 2015 \\
\hline 27 & Estimating the revenue gained from & Amiri.Z; \& Amiri.M. & 2015 \\
\hline 28 & receiving the facilities & Azadi Moghaddam Arani et al. & 2004 \\
\hline 29 & Liquidity level & Azadi Moghaddam Arani et al. & 2004 \\
\hline 30 & Estimating rate of return & Karimi et al. & 2015 \\
\hline
\end{tabular}

Additionally, at the end of the first round, the respondents identified other factors that are effective in granting banking facilities. These factors include location of the facilities granted and type of using the facilities in that region, financial transparency, work honesty, considering the professional ethics, capacity assessment, short term facilities and customer personality.

Table 3: Delphi second round results

\begin{tabular}{|c|c|c|c|c|c|c|c|}
\hline \multirow[b]{2}{*}{ Row } & \multirow[b]{2}{*}{ Factors } & \multicolumn{5}{|c|}{ The level of importance of the respondents } & \multirow[t]{2}{*}{ Mean } \\
\hline & & $\begin{array}{l}\text { Very } \\
\text { low }\end{array}$ & Low & Moderate & High & $\begin{array}{l}\text { Very } \\
\text { high }\end{array}$ & \\
\hline 1 & Having previous liabilities & 0 & 6 & 19 & 32 & 43 & 4.096774 \\
\hline 2 & Respiration time & 19 & 23 & 42 & 13 & 3 & 2.580645 \\
\hline 3 & Level of facilities & 0 & 10 & 23 & 32 & 35 & 3.935484 \\
\hline 4 & Customer capital level & 3 & 0 & 13 & 45 & 39 & 4.16129 \\
\hline 5 & History of activity & 0 & 3 & 7 & 39 & 51 & 4.387097 \\
\hline 6 & Ratio of current asset & 0 & 6 & 32 & 43 & 19 & 3.741935 \\
\hline 7 & $\begin{array}{l}\text { Period of inventory turnover per } \\
\text { day }\end{array}$ & 3 & 6 & 46 & 29 & 16 & 3.483871 \\
\hline 8 & $\begin{array}{l}\text { Period of collecting the debts per } \\
\text { day }\end{array}$ & 10 & 3 & 29 & 42 & 16 & 3.516129 \\
\hline 9 & Ownership ratio & 3 & 6 & 19 & 35 & 37 & 3.935484 \\
\hline 10 & Debt ratio & 7 & 10 & 33 & 27 & 23 & 3.5 \\
\hline 11 & Good reputation of the applicant & 0 & 3 & 23 & 42 & 32 & 4.032258 \\
\hline 12 & Liquidity ratio & 0 & 10 & 26 & 29 & 35 & 3.903226 \\
\hline 13 & Balance Sheet & 0 & 6 & 26 & 39 & 29 & 3.903226 \\
\hline 14 & $\begin{array}{l}\text { Conditions and standards for } \\
\text { granting facilities }\end{array}$ & 0 & 6 & 35 & 23 & 36 & 3.870968 \\
\hline 15 & Level of asset owned & 0 & 6 & 26 & 36 & 32 & 3.935484 \\
\hline 16 & Average of account turnover & 0 & 6 & 32 & 23 & 39 & 3.935484 \\
\hline 17 & Current capital to total asset & 0 & 13 & 52 & 16 & 19 & 3.419355 \\
\hline 18 & $\begin{array}{l}\text { Financial statements (profit and } \\
\text { loss) }\end{array}$ & 0 & 10 & 29 & 29 & 32 & 3.83871 \\
\hline
\end{tabular}




\begin{tabular}{|c|c|c|c|c|c|c|c|}
\hline 19 & Type of facilities granted & 3 & 13 & 32 & 36 & 16 & 3.483871 \\
\hline 20 & Insurance of facilities & 13 & 19 & 46 & 19 & 3 & 2.806452 \\
\hline 21 & Location for use of facilities & 3 & 23 & 26 & 32 & 16 & 3.354839 \\
\hline 22 & $\begin{array}{l}\text { Needs assessment and feasibility } \\
\text { assessment of facilities }\end{array}$ & 3 & 10 & 29 & 39 & 19 & 3.612903 \\
\hline 23 & Duration of facilities & 0 & 6 & 45 & 26 & 23 & 3.645161 \\
\hline 24 & Type of collateral & 0 & 3 & 13 & 49 & 35 & 4.16129 \\
\hline 25 & $\begin{array}{l}\text { Obligatory or non-obligatory } \\
\text { facilities }\end{array}$ & 9 & 23 & 35 & 10 & 23 & 3.129032 \\
\hline 26 & History of receiving other facilities & 10 & 3 & 39 & 29 & 19 & 3.451613 \\
\hline 27 & Having justification project & 6 & 13 & 29 & 23 & 29 & 3.548387 \\
\hline 28 & $\begin{array}{l}\text { Estimating revenue gained from } \\
\text { receiving the facilities }\end{array}$ & 3 & 6 & 36 & 29 & 26 & 3.677419 \\
\hline 29 & Liquidity level & 10 & 6 & 39 & 26 & 19 & 3.387097 \\
\hline 30 & Estimating the rate of return & 3 & 0 & 26 & 35 & 36 & 4 \\
\hline 31 & $\begin{array}{l}\text { Location for using facilities granted } \\
\text { and type of the facilities granted for } \\
\text { than region }\end{array}$ & 0 & 0 & 10 & 29 & 61 & 4.516129 \\
\hline 32 & Financial transparency & 0 & 3 & 52 & 45 & 0 & 3.419355 \\
\hline 33 & Work honesty & 0 & 0 & 52 & 48 & 0 & 3.483871 \\
\hline 34 & Considering the professional ethics & 0 & 3 & 65 & 32 & 0 & 3.290323 \\
\hline 35 & Capacity assessment & 0 & 6 & 49 & 39 & 6 & 3.451613 \\
\hline 36 & Short-term facilities & 68 & 19 & 13 & 0 & 0 & 1.451613 \\
\hline 37 & Customer personality & 0 & 10 & 52 & 35 & 3 & 3.322581 \\
\hline
\end{tabular}

In the second round, the experts' opinions were collected through a questionnaire. A total of 37 factors were used to select the factors that are most important in this step. All items were deigned on the 5-point Likert scale based on their importance (very high $=5$, high $=4$, moderate $=3$, low $=2$ and very low $=1$ ) to determine the importance of each of the factors. In this step, the considered level of agreement for selection of the factors based on the opinion of the experts was the mean score of 4 and higher. The mean score 4 indicates high and very high agreement among the group members. In this round, 7 factors were selected. Then, in the third step, Delphi method was used to review the results. In the third round, the factors with mean scores of above 4 were obtained, indicating closeness of the opinions. Hence, Delphi method was stopped in the third round and 7 factors were selected. The results of factor identification are presented in Table 3.

Table 4: The key factors affecting the granting of banking facilities

\begin{tabular}{|c|c|c|c|}
\hline Row & Factors & Row & Factors \\
\hline 1 & Estimating the rate of return & 2 & History of activity \\
\hline 3 & Level of customer capital & 4 & Type of collateral \\
\hline 5 & Having previous liabilities & 6 & Good reputation of applicant \\
\hline 7 & \multicolumn{3}{|c|}{ Location for use of facilities grated and type of using the facilities in that region } \\
\hline
\end{tabular}

As the effective weight of each of the key and important factors is used in the next steps of the research, by using Saaty pairwise comparisons, these factors were compared in pairs by 10 experts.

Step 1: Matrix of $\mathrm{K}$ expert pairwise comparisons matrix is defined as matrix (1).

Step 2: The experts' pairwise comparisons were examined in terms of inconsistency rates by Expert Choice software and if the inconsistency rate is less than 0.1 , the pairwise comparison is consistent and if it is greater than 0.1 , the pairwise comparison numbers should be corrected. 


$$
\begin{aligned}
& B_{1}=\left[\begin{array}{ccccccc}
1 & 1.8 & 1.2 & 1.3 & 1.7 & 1.6 & 1.7 \\
8 & 1 & 4 & 2 & 1 & 4 & 1.2 \\
2 & 1.4 & 1 & 1.3 & 1.5 & 1.2 & 1.5 \\
3 & 1.2 & 3 & 1 & 1 & 1.3 & 1.2 \\
7 & 1 & 5 & 1 & 1 & 4 & 1.2 \\
6 & 1.4 & 2 & 3 & 1.4 & 1 & 1.3 \\
7 & 2 & 5 & 2 & 2 & 3 & 1
\end{array}\right], C R_{1}=0.07<0.1 \\
& B_{2}=\left[\begin{array}{ccccccc}
1 & 1.4 & 1.3 & 1.5 & 1.5 & 1.2 & 1.7 \\
4 & 1 & 3 & 1.2 & 1 & 4 & 1.3 \\
3 & 1.3 & 1 & 1.2 & 1.3 & 4 & 1.5 \\
5 & 2 & 2 & 1 & 1 & 5 & 1.2 \\
5 & 1 & 3 & 1 & 1 & 6 & 1.2 \\
2 & 1.4 & 1.4 & 1.5 & 1.6 & 1 & 1.5 \\
7 & 3 & 5 & 2 & 2 & 5 & 1
\end{array}\right], C R_{2}=0.04<0.1 \\
& B_{3}=\left[\begin{array}{ccccccc}
1 & 1.4 & 1.2 & 1.3 & 1.4 & 1.2 & 1.8 \\
4 & 1 & 3 & 2 & 2 & 3 & 1.2 \\
2 & 1.3 & 1 & 1.2 & 1.2 & 2 & 1.4 \\
3 & 1.2 & 2 & 1 & 1 & 1.3 & 1.2 \\
4 & 1.2 & 2 & 1 & 1 & 2 & 1.2 \\
2 & 1.3 & 1.2 & 3 & 1.2 & 1 & 1.3 \\
8 & 2 & 4 & 2 & 2 & 3 & 1
\end{array}\right], C R_{3}=0.06<0.1 \\
& B_{4}=\left[\begin{array}{ccccccc}
1 & 1 & 1 & 1.3 & 1.3 & 1.2 & 1 \\
1 & 1 & 1 & 1.3 & 1.3 & 1 & 1.3 \\
1 & 1 & 1 & 1.3 & 1.3 & 1 & 1.3 \\
3 & 3 & 3 & 1 & 1 & 1 & 3 \\
3 & 3 & 3 & 1 & 1 & 3 & 1 \\
2 & 1 & 1 & 1 & 1.3 & 1 & 1 \\
1 & 3 & 3 & 1.3 & 1 & 1 & 1
\end{array}\right], C R_{4}=0.05<0.1 \\
& B_{5}=\left[\begin{array}{ccccccc}
1 & 1.3 & 1.2 & 1.4 & 1.4 & 1 & 1.5 \\
3 & 1 & 3 & 1 & 1 & 3 & 1.3 \\
2 & 1.3 & 1 & 1.2 & 1.3 & 4 & 1.2 \\
4 & 1 & 2 & 1 & 1 & 4 & 1.2 \\
4 & 1 & 3 & 1 & 1 & 3 & 1.2 \\
1 & 1.3 & 1.4 & 1.4 & 1.3 & 1 & 1.5 \\
5 & 3 & 2 & 2 & 2 & 5 & 1
\end{array}\right], C R_{5}=0.03<0.1 \\
& B_{6}=\left[\begin{array}{ccccccc}
1 & 3 & 5 & 3 & 3 & 1 & 3 \\
1.3 & 1 & 4 & 1 & 1 & 1.3 & 1 \\
1.5 & 1.4 & 1 & 1.3 & 1.3 & 1.5 & 1.3 \\
1.3 & 1 & 3 & 1 & 1 & 1.3 & 1 \\
1.3 & 1 & 3 & 1 & 1 & 1.3 & 1 \\
1 & 3 & 5 & 3 & 3 & 1 & 3 \\
1.3 & 1 & 3 & 1 & 1 & 1.3 & 1
\end{array}\right], C R_{6}=0.01<0.1 \\
& B_{7}=\left[\begin{array}{ccccccc}
1 & 1.3 & 1.2 & 1.4 & 1.3 & 2 & 1.5 \\
3 & 1 & 1.2 & 1.2 & 1 & 3 & 1.4 \\
2 & 2 & 1 & 1.2 & 1.2 & 3 & 1.2 \\
4 & 2 & 2 & 1 & 1 & 3 & 1.2 \\
3 & 1 & 2 & 1 & 1 & 3 & 1.2 \\
1.2 & 1.3 & 1.3 & 1.3 & 1.3 & 1 & 1.3 \\
5 & 4 & 2 & 2 & 2 & 3 & 1
\end{array}\right], C R_{7}=0.04<0.1 \\
& B_{8}=\left[\begin{array}{ccccccc}
1 & 1.3 & 1.3 & 1.4 & 1.5 & 1 & 1.7 \\
3 & 1 & 4 & 1 & 1 & 3 & 1.3 \\
3 & 1.2 & 1 & 1.2 & 1.3 & 4 & 1.2 \\
4 & 1 & 2 & 1 & 1 & 3 & 1.2 \\
5 & 1 & 3 & 1 & 1 & 3 & 1.2 \\
1 & 1.3 & 1.4 & 1.3 & 1.3 & 1 & 1.5 \\
7 & 3 & 2 & 2 & 2 & 5 & 1
\end{array}\right], C R_{8}=0.04<0.1
\end{aligned}
$$




$$
\begin{aligned}
& B_{9}=\left[\begin{array}{ccccccc}
1 & 1.3 & 1.2 & 1.4 & 1.3 & 3 & 1.5 \\
3 & 1 & 2 & 1 & 1 & 3 & 1.2 \\
2 & 1.2 & 1 & 1.2 & 1.3 & 2 & 1.2 \\
4 & 1 & 2 & 1 & 1 & 4 & 1.2 \\
3 & 1 & 3 & 1 & 1 & 4 & 1.2 \\
1.3 & 1.3 & 1.2 & 1.4 & 1.4 & 1 & 1.4 \\
5 & 2 & 2 & 2 & 2 & 4 & 1
\end{array}\right], C R_{9}=0.03<0.1 \\
& B_{10}=\left[\begin{array}{ccccccc}
1 & 1 & 5 & 3 & 3 & 1 & 3 \\
1 & 1 & 5 & 3 & 3 & 1 & 3 \\
1.5 & 1.5 & 1 & 1.4 & 1.4 & 1.5 & 1.4 \\
1.3 & 1.3 & 4 & 1 & 1 & 1.3 & 1 \\
1.3 & 1.3 & 4 & 1 & 1 & 1.3 & 1 \\
1 & 1 & 5 & 3 & 3 & 1 & 3 \\
1.3 & 1.3 & 4 & 1 & 1 & 1.3 & 1
\end{array}\right], C R_{10}=0.02<0.1
\end{aligned}
$$

It can be clearly abserved that $C R_{e}<0.1(e=1,2, \ldots, 10)$; therefore, all pairwise matrices are acceptable. Group pairwise matrix $\tilde{B}$ is created by integrating 10 pairwise matrices.

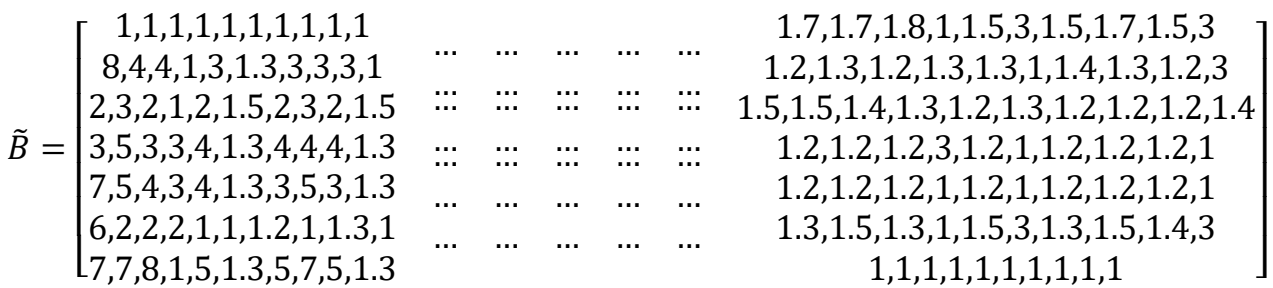

Step 3: Transforming the factors in $\tilde{B}$ as Rough number

Consider $\tilde{x}_{41}=\{3,5,3,3,4,1.3,4,4,4,1.3\}$ as an example.

$\underline{\lim }(1.3)=\frac{1}{3}=0.333333, \quad \overline{\lim }(1.3)=\sqrt[4]{\frac{1}{3} \times 3 \times 4 \times 5}=2.282617$

$\underline{\lim }(3)=\sqrt{1.3 \times 3}=1.24573, \quad \underline{\lim }(3)=\sqrt[3]{3 \times 4 \times 5}=3.69251$

$\underline{\lim }(4)=\sqrt[3]{1.3 \times 3 \times 4}=2.092163, \quad \overline{\lim }(4)=\sqrt[2]{4 \times 5}=4.182558$

$\underline{\lim }(5)=\sqrt[4]{1.3 \times 3 \times 4 \times 5}=2.282617, \quad \overline{\lim }(5)=5$

Hence, $x_{41}^{e}$ can be stated as Rough number

$R N\left(x_{41}^{6}\right)=R N\left(x_{41}^{10}\right)=[0.333333,2.282617]$

$R N\left(x_{41}^{1}\right)=R N\left(x_{41}^{3}\right)=R N\left(x_{41}^{4}\right)=[1.24573,3.69251]$

$R N\left(x_{41}^{5}\right)=R N\left(x_{41}^{7}\right)=R N\left(x_{41}^{8}\right)=R N\left(x_{41}^{9}\right)=[2.092163,4.182558]$

$R N\left(x_{41}^{2}\right)=[2.282617,5]$

Using the equation (2):

$X_{41}^{L}$

$=\sqrt[10]{0.333333 \times 0.333333 \times 1.24573 \times 1.24573 \times 1.24573 \times 2.092163 \times 2.092163 \times 2.092163 \times 2.092163 \times 2.282617}$

$=1.251078$

$X_{41}^{U}$

$=\sqrt[10]{2.282617 \times 2.282617 \times 3.69251 \times 3.69251 \times 3.69251 \times 4.182558 \times 4.182558 \times 4.182558 \times 4.182558 \times 5}$ $=3.633766$

Accordingly, Rough sequence $x_{41}^{e}$ in $\tilde{B}$ is transformed to Rough number $R N\left(X_{41}\right)=$ [1.251078,3.633766]. Transforming other factors in $\tilde{B}$ is done accordingly.

$$
M=\left[\begin{array}{ccccccc}
{[1,1]} & & & & & & {[0.185922,0.928054]} \\
{[1.248027,3.844867]} & \ldots & \ldots & \ldots & \ldots & \ldots & {[0.349659,0.81826]} \\
{[0.694285,2.104101]} & \ldots & \ldots & \ldots & \ldots & \ldots & {[0.26372,0.424983]} \\
{[1.251078,3.633766]} & \ldots & \ldots & \ldots & \ldots & \ldots & {[0.532294,0.923451]} \\
{[1.227177,4.298947]} & \ldots & \ldots & \ldots & \ldots & \ldots & {[0.532185,0.712025]} \\
{[0.749375,2.052754]} & \ldots & \ldots & \ldots & \ldots & \ldots & {[0.269569,0.983278]} \\
{[1.254036,5.574769]} & & & & & & {[1,1]}
\end{array}\right]
$$

Step 4: Calculating the Rough weigh of the factors using equations (4) and (5): 
$W=\left\{w_{1}, w_{2}, w_{3}, w_{4}, w_{5}, w_{6}, w_{7}\right\}$

$W=\left\{\begin{array}{c}{[0.355436,0.989829],[0.886935,1.864221],[0.437424,0.847499],[0.911171,1.669128],} \\ {[1.040019,1.729961],[0.439585,1.247092],[1.278313,2.594654]}\end{array}\right\}$

Hence, normal form of $\mathrm{w}^{\prime}$ is obtained.

$W^{\prime}=\left\{\begin{array}{c}{[0.136988,0.381488],[0.341832,0.718485],[0.168587,0.326633],[0.351172,0.643295],} \\ {[0.400831,0.666741],[0.16942,0.480639],[0.492672,1]}\end{array}\right\}$

Table 5- The weight of the key and affective factors

\begin{tabular}{|c|c|c|}
\hline Row & Criterion & {$\left[W_{j}^{L}, W_{j}^{U}\right]$} \\
\hline 1 & Location for use of facilities grated and type of using the facilities in that region & {$[0.136988,0.381488]$} \\
\hline 2 & History of activity & {$[0.341832,0.718485]$} \\
\hline 3 & Level of customer capital & {$[0.168587,0.326633]$} \\
\hline 4 & Type of collateral & {$[0.351172,0.643295]$} \\
\hline 5 & Having previous liabilities & {$[0.400831,0.666741]$} \\
\hline 6 & Good reputation of applicant & {$[0.16942,0.480639]$} \\
\hline 7 & Estimating rate of return & {$[0.492672,1]$} \\
\hline
\end{tabular}

The steps for the Rough VIKOR method to rank customers are as follows:

Step 1: Forming the individual decision matrix is done through using the opinions of three banking experts and transforming their component fij in the F matrix to the Rough number to form the Rough F group evaluation matrix. After calculation, the F matrix was completed. The elements of this matrix include the Rough number ranges. These elements are listed in Table (4).

Table 6= Matrix F

\begin{tabular}{|c|c|c|c|c|c|}
\hline elements & {$\left[f_{i j}^{L}, f_{i j}^{U}\right]$} & elements & {$\left[f_{i j}^{L}, f_{i j}^{U}\right]$} & elements & {$\left[f_{i j}^{L}, f_{i j}^{U}\right]$} \\
\hline $\mathrm{f} 11$ & {$[7.198221,8.162016]$} & $\mathrm{f} 76$ & {$[8.105384,8.597058]$} & $\mathrm{f} 144$ & {$[4.362618,4.877556]$} \\
\hline $\mathrm{f} 12$ & {$[4.764074,6.302277]$} & $\mathrm{f} 77$ & {$[7.470232,8.470447]$} & $\mathrm{f} 145$ & {$[3.355124,3.874163]$} \\
\hline $\mathrm{f} 13$ & {$[5.541723,7.009786]$} & $\mathrm{f} 81$ & {$[7.470232,8.470447]$} & $\mathrm{f} 146$ & {$[6.103652,6.592698]$} \\
\hline $\mathrm{f} 14$ & {$[6.465910,7.466190]$} & $\mathrm{f} 82$ & {$[5.784171,7.316462]$} & $\mathrm{f} 147$ & {$[8.374958,8.882984]$} \\
\hline $\mathrm{f} 15$ & {$[4.100415,4.584403]$} & $\mathrm{f} 33$ & {$[2.417642,3.419062]$} & $\mathrm{f} 151$ & {$[6.370685,6.881126]$} \\
\hline $\mathrm{f} 16$ & {$[8.105384,8.597058]$} & $\mathrm{f} 84$ & {$[3.439350,4.440181]$} & $\mathrm{f} 152$ & {$[5.784171,7.316462]$} \\
\hline $\mathrm{f} 17$ & {$[7.470232,8.470447]$} & $\mathrm{f} 85$ & {$[4.100415,4.584403]$} & $\mathrm{f} 153$ & {$[5.259746,5.589314]$} \\
\hline $\mathrm{f} 21$ & {$[7.373106,7.882182]$} & $\mathrm{f} 86$ & {$[5.460108,6.460487]$} & $\mathrm{f} 154$ & {$[4.528805,5.991047]$} \\
\hline $\mathrm{f} 22$ & {$[6.465910,7.466190]$} & $\mathrm{f} 87$ & {$[5.102323,5.589314]$} & $\mathrm{f} 155$ & {$[5.367385,5.879675]$} \\
\hline $\mathrm{f} 23$ & {$[2.417642,3.419062]$} & $\mathrm{f} 91$ & {$[8.105384,8.597058]$} & $\mathrm{f} 156$ & {$[5.367385,5.879675]$} \\
\hline $\mathrm{f} 24$ & {$[3.355124,3.874163]$} & $\mathrm{f} 92$ & {$[7.470232,8.470447]$} & $\mathrm{f} 157$ & {$[4.100415,4.584403]$} \\
\hline $\mathrm{f} 25$ & {$[3.097443,3.576619]$} & $\mathrm{f} 93$ & {$[5.460108,6.460487]$} & $\mathrm{f} 161$ & {$[8.374958,8.882984]$} \\
\hline f26 & {$[5.102323,5.589314]$} & $\mathrm{f} 94$ & {$[4.451897,5.452438]$} & $\mathrm{f} 162$ & {$[5.460108,6.460487]$} \\
\hline f27 & {$[5.784171,7.316462]$} & $\mathrm{f} 95$ & {$[5.784171,7.316462]$} & $\mathrm{f} 163$ & {$[6.465910,7.466190]$} \\
\hline f31 & {$[7.104632,7.595171]$} & $\mathrm{f} 96$ & {$[6.103652,6.592698]$} & $\mathrm{f} 164$ & {$[7.470232,8.470447]$} \\
\hline $\mathrm{f} 32$ & {$[7.470232,8.470447]$} & $\mathrm{f} 97$ & {$[5.268051,6.663616]$} & $\mathrm{f} 165$ & {$[2.478334,3.918590]$} \\
\hline
\end{tabular}




\begin{tabular}{|c|c|c|c|c|c|}
\hline f33 & {$[1.622546,3.628123]$} & f101 & {$[7.470232,8.470447]$} & f166 & {$[5.460108,6.460487]$} \\
\hline f34 & {$[2.914623,5.048275]$} & f102 & {$[4.451897,5.452438]$} & f167 & [6.798642,8.326601] \\
\hline f35 & {$[4.451897,5.452438]$} & f103 & {$[7.104632,7.595171]$} & f171 & {$[5.784171,7.316462]$} \\
\hline f36 & {$[4.764074,6.302277]$} & f104 & {$[3.439350,4.440181]$} & f172 & {$[3.439350,4.440181]$} \\
\hline f37 & {$[5.784171,7.316462]$} & f105 & {$[3.175200,4.099166]$} & f173 & {$[2.092164,2.562367]$} \\
\hline $\mathrm{f} 41$ & {$[8.105384,8.597058]$} & f106 & {$[5.102323,5.589314]$} & f174 & {$[2.092164,2.562367]$} \\
\hline $\mathrm{f} 42$ & {$[5.784171,7.316462]$} & f107 & {$[3.439350,4.440181]$} & f175 & {$[4.100415,4.584403]$} \\
\hline $\mathrm{f} 43$ & {$[2.478334,3.918590]$} & f111 & {$[6.551086,8.023409]$} & f176 & {$[3.097443,3.576619]$} \\
\hline $\mathrm{f} 44$ & {$[5.460108,6.460487]$} & f112 & {$[3.509734,4.963514]$} & f177 & {$[4.100415,4.584403]$} \\
\hline $\mathrm{f} 45$ & {$[4.362618,4.877556]$} & f113 & {$[3.509734,4.963514]$} & f181 & {$[4.451897,5.452438]$} \\
\hline $\mathrm{f} 46$ & {$[3.570366,5.453825]$} & f114 & {$[3.659281,4.724112]$} & f182 & {$[5.460108,6.460487]$} \\
\hline $\mathrm{f} 47$ & {$[4.100415,4.584403]$} & f115 & {$[4.528805,5.991047]$} & f183 & {$[3.734167,5.280909]$} \\
\hline f51 & {$[7.470232,8.470447]$} & f116 & {$[4.451897,5.452438]$} & f184 & {$[2.739447,4.744861]$} \\
\hline f52 & {$[7.104632,7.595171]$} & f117 & {$[3.439350,4.440181]$} & f185 & {$[2.478334,3.918590]$} \\
\hline f53 & {$[3.734167,5.280909]$} & $\mathrm{f} 121$ & {$[2.684510,4.244583]$} & f186 & {$[5.784171,7.316462]$} \\
\hline f54 & {$[3.659281,4.724112]$} & f122 & {$[4.451897,5.452438]$} & f187 & {$[7.470232,8.470447]$} \\
\hline f55 & {$[3.439350,4.440181]$} & f123 & {$[3.439350,4.440181]$} & f191 & {$[5.102323,5.589314]$} \\
\hline f56 & {$[3.570366,5.453825]$} & f124 & {$[4.451897,5.452438]$} & f192 & {$[3.000000,3.000000]$} \\
\hline f57 & {$[4.451897,5.452438]$} & f125 & {$[2.684510,4.244583]$} & f193 & {$[3.439350,4.440181]$} \\
\hline f61 & {$[3.175200,4.099166]$} & f126 & {$[5.460108,6.460487]$} & f194 & {$[2.341585,2.867844]$} \\
\hline f62 & {$[4.528805,5.991047]$} & $\mathrm{f} 127$ & {$[5.784171,7.316462]$} & f195 & {$[2.092164,2.562367]$} \\
\hline f63 & {$[3.439350,4.440181]$} & f131 & {$[7.373106,7.882182]$} & f196 & {$[4.100415,4.584403]$} \\
\hline f64 & {$[8.374958,8.882984]$} & f132 & {$[4.451897,5.452438]$} & f197 & {$[4.362618,4.877556]$} \\
\hline f65 & [3.175200,4.099166] & f133 & {$[4.528805,5.991047]$} & f201 & {$[3.509734,4.963514]$} \\
\hline f66 & {$[6.465910,7.466190]$} & f134 & {$[4.362618,4.877556]$} & $\mathrm{f} 202$ & {$[3.355124,3.874163]$} \\
\hline f67 & {$[8.374958,8.710307]$} & f135 & {$[4.362618,4.877556]$} & $\mathrm{f} 203$ & {$[5.102323,5.589314]$} \\
\hline $\mathrm{f} 71$ & {$[7.373106,7.882182]$} & f136 & {$[4.100415,4.584403]$} & f204 & {$[4.362618,4.877556]$} \\
\hline $\mathrm{f} 72$ & {$[4.451897,5.452438]$} & f137 & {$[4.362618,4.877556]$} & f205 & {$[6.798642,8.326601]$} \\
\hline $\mathrm{f} 73$ & {$[7.104632,7.595171]$} & f141 & {$[7.373106,7.882182]$} & f206 & {$[5.784171,7.316462]$} \\
\hline $\mathrm{f} 74$ & {$[8.374958,8.882984]$} & $\mathrm{f} 142$ & {$[4.100415,4.584403]$} & f207 & {$[4.451897,5.452438]$} \\
\hline $\mathrm{f} 75$ & {$[3.439350,4.440181]$} & f143 & {$[4.100415,4.584403]$} & & \\
\hline
\end{tabular}


Step 2: In this step, the ideal positive and negative options will be identified. The result of the calculations is as described in Table (5).

Table 7: The ideal positive and negative options

\begin{tabular}{|c|c|c|c|}
\hline Row & Criterion & $f_{j}^{-}$ & $f_{j}^{*}$ \\
\hline 1 & $\begin{array}{c}\text { Location for use of facilities grated and type of using the } \\
\text { facilities in that region }\end{array}$ & 2.684510 & 8.882984 \\
\hline 2 & History of activity & 3.000000 & 8.470447 \\
\hline 3 & Level of customer capital & 1.622546 & 7.595171 \\
\hline 4 & Type of collateral & 2.092164 & 8.882984 \\
\hline 5 & Having previous liabilities & 2.092164 & 8.326601 \\
\hline 6 & Good reputation of applicant & 3.097443 & 8.597058 \\
\hline 7 & Estimating rate of return & 3.439350 & 8.882984 \\
\hline
\end{tabular}

Step 3: In this step, the value of the utility index and the regret index of the options will be calculated. The values of utility and regret indices are in accordance with Table (8) and Table (9).

Table 8: The utility index values (options)

\begin{tabular}{|c|c|c|c|}
\hline Row & {$\left[S_{i}^{L}, S_{i}^{U}\right]$} & Row & {$\left[S_{i}^{L}, S_{i}^{U}\right]$} \\
\hline 1 & {$[1.385650,2.657571]$} & 11 & {$[2.788113,5.673882]$} \\
\hline 2 & {$[2.316535,4.551897]$} & 12 & {$[2.501978,5.093535]$} \\
\hline 3 & {$[1.962679,3.906624]$} & 13 & {$[2.578267,5.244419]$} \\
\hline 4 & {$[2.364129,4.779473]$} & 14 & {$[1.986333,3.896541]$} \\
\hline 5 & {$[2.367162,4.729707]$} & 15 & {$[2.189650,4.472163]$} \\
\hline 6 & {$[1.630819,3.350135]$} & 16 & {$[1.515697,2.975189]$} \\
\hline 7 & {$[1.279727,2.470226]$} & 17 & {$[3.303014,6.735270]$} \\
\hline 8 & {$[2.370606,4.677411]$} & 18 & {$[2.144154,4.244821]$} \\
\hline 9 & {$[1.479836,2.965150]$} & 19 & {$[3.500888,7.054723]$} \\
\hline 10 & {$[2.703206,5.387334]$} & 20 & {$[2.315947,4.866462]$} \\
\hline
\end{tabular}


Table 9- The regret index values of customers (options)

\begin{tabular}{|c|c|c|c|}
\hline row & {$\left[R_{i}^{L}, R_{i}^{U}\right]$} & row & {$\left[R_{i}^{L}, R_{i}^{U}\right]$} \\
\hline 1 & {$[0.271714,0.486792]$} & 11 & {$[0.492672,1]$} \\
\hline 2 & {$[0.336198,0.569254]$} & 12 & {$[0.362747,0.603392]$} \\
\hline 3 & {$[0.308640,0.569254]$} & 13 & {$[0.409112,0.830394]$} \\
\hline 4 & {$[0.432842,0.878561]$} & 14 & {$[0.319631,0.573957]$} \\
\hline 5 & {$[0.401032,0.813994]$} & 15 & {$[0.432842,0.878561]$} \\
\hline 6 & {$[0.331199,0.550915]$} & 16 & {$[0.376002,0.625442]$} \\
\hline 7 & {$[0.314216,0.527793]$} & 17 & {$[0.432842,0.878561]$} \\
\hline 8 & {$[0.342165,0.694510]$} & 18 & {$[0.376002,0.625442]$} \\
\hline 9 & {$[0.327166,0.664066]$} & 19 & {$[0.409112,0.830394]$} \\
\hline 10 & {$[0.492672,1]$} & 20 & {$[0.401032,0.813994]$} \\
\hline
\end{tabular}

Step 4: In this step, we calculate the VIKOR Q index. In this step, the value of V is considered 0.5. The values of the VIKOR index can be seen in Table (10).

Table 10: The VIKOR Index values

\begin{tabular}{|c|c|c|c|}
\hline row & {$\left[Q_{i}^{L}, Q_{i}^{U}\right]$} & {$\left[Q_{i}^{L}, Q_{i}^{U}\right]$} \\
\hline 1 & {$[0.009170,0.266954]$} & 11 & {$[0.282293,0.880446]$} \\
\hline 2 & {$[0.134038,0.487579]$} & 12 & {$[0.168320,0.557911]$} \\
\hline 3 & {$[0.084481,0.431711]$} & 13 & {$[0.206757,0.726822]$} \\
\hline 4 & {$[0.204509,0.719635]$} & 14 & {$[0.094075,0.434067]$} \\
\hline 5 & {$[0.182932,0.670998]$} & 15 & {$[0.189403,0.693028]$} \\
\hline 6 & {$[0.071236,0.370940]$} & 16 & {$[0.092028,0.389642]$} \\
\hline 7 & {$[0.029179,0.278883]$} & 17 & {$[0.285798,0.888969]$} \\
\hline 8 & {$[0.142816,0.584440]$} & 18 & {$[0.146440,0.499567]$} \\
\hline 9 & {$[0.055395,0.415290]$} & 19 & {$[0.286638,0.883558]$} \\
\hline 10 & {$[0.274942,0.855637]$} & 20 & {$[0.178498,0.682838]$} \\
\hline
\end{tabular}

Step 5: In this step, the descending ranking of the customers (options) will be done based on the values of VIKOR, utility and regret indices and weight of the effective factors will be determined. This ranking can be seen in Table 11 . 
Table 11: Descending ranking based on the values of VIKOR, utility and regret

\begin{tabular}{|c|c|c|c|c|c|}
\hline 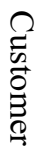 & $S_{i}$ & 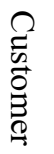 & $R_{i}$ & 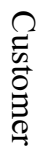 & $Q_{i}$ \\
\hline 7 & {$[1.279727,2.470226]$} & 1 & {$[0.271714,0.486792]$} & 1 & {$[0.009170,0.266954]$} \\
\hline 1 & {$[1.385650,2.657571]$} & 3 & {$[0.308640,0.569254]$} & 7 & {$[0.029179,0.278883]$} \\
\hline 9 & {$[1.479836,2.965150]$} & 7 & {$[0.314216,0.527793]$} & 9 & {$[0.055395,0.415290]$} \\
\hline 16 & {$[1.515697,2.975189]$} & 14 & {$[0.319631,0.573957]$} & 6 & {$[0.071236,0.370940]$} \\
\hline 6 & {$[1.630819,3.350135]$} & 9 & {$[0.327166,0.664066]$} & 3 & {$[0.084481,0.431711]$} \\
\hline 3 & {$[1.962679,3.906624]$} & 6 & {$[0.331199,0.550915]$} & 16 & {$[0.092028,0.389642]$} \\
\hline 14 & {$[1.986333,3.896541]$} & 2 & {$[0.336198,0.569254]$} & 14 & {$[0.094075,0.434067]$} \\
\hline 18 & {$[2.144154,4.244821]$} & 8 & {$[0.342165,0.694510]$} & 2 & {$[0.134038,0.487579]$} \\
\hline 15 & {$[2.189650,4.472163]$} & 12 & {$[0.362747,0.603392]$} & 8 & {$[0.142816,0.584440]$} \\
\hline 20 & {$[2.315947,4.866462]$} & 16 & {$[0.376002,0.625442]$} & 18 & {$[0.146440,0.499567]$} \\
\hline 2 & {$[2.316535,4.551897]$} & 18 & {$[0.376002,0.625442]$} & 12 & {$[0.168320,0.557911]$} \\
\hline 4 & {$[2.364129,4.779473]$} & 5 & {$[0.401032,0.813994]$} & 20 & {$[0.178498,0.682838]$} \\
\hline 5 & {$[2.367162,4.729707]$} & 20 & {$[0.401032,0.813994]$} & 5 & {$[0.182932,0.670998]$} \\
\hline 8 & {$[2.370606,4.677411]$} & 13 & {$[0.409112,0.830394]$} & 15 & {$[0.189403,0.693028]$} \\
\hline 12 & {$[2.501978,5.093535]$} & 19 & {$[0.409112,0.830394]$} & 4 & {$[0.204509,0.719635]$} \\
\hline 13 & {$[2.578267,5.244419]$} & 4 & {$[0.432842,0.878561]$} & 13 & {$[0.206757,0.726822]$} \\
\hline 10 & {$[2.703206,5.387334]$} & 15 & {$[0.432842,0.878561]$} & 10 & {$[0.274942,0.855637]$} \\
\hline 11 & {$[2.788113,5.673882]$} & 17 & {$[0.432842,0.878561]$} & 11 & {$[0.282293,0.880446]$} \\
\hline 17 & {$[3.303014,6.735270]$} & 10 & {$[0.492672,1]$} & 17 & {$[0.285798,0.888969]$} \\
\hline 19 & {$[3.500888,7.054723]$} & 11 & {$[0.492672,1]$} & 19 & {$[0.286638,0.883558]$} \\
\hline
\end{tabular}

Step 6: In this step, given the descending ranking of the previous step, the final ranking of options (customers who received the facilities) is presented. The final ranking of the customers received the facilities is shown in Table 12.

For the first and second final rank, that is customer 7 and 1, we first examine the first conditions for these two options. The results show that the first condition has not been met but the second has been met. When the first condition is not met, the equation (34) is used to obtain the optimal VIKOR index.

$$
\begin{aligned}
& \sqrt{1.2\left[\left(Q^{U}\left(A_{b}\right)-Q^{U}\left(A_{a}\right)\right)^{2}+\left(Q^{L}\left(A_{b}\right)-Q^{L}\left(A_{a}\right)\right)^{2}\right]} \geq \frac{1}{m-1} \\
& \sqrt{1.2\left[(0.278883-0.266954)^{2}+(0.029179-0.009170)^{2}\right]} \geq \frac{1}{20-1} \\
& \sqrt{0.000271}=0.01646<0.052631
\end{aligned}
$$




$$
\begin{aligned}
& \sqrt{1 / 2\left[\left(Q^{U}\left(A_{k}\right)-Q^{U}\left(A_{a}\right)\right)^{2}+\left(Q^{L}\left(A_{k}\right)-Q^{L}\left(A_{a}\right)\right)^{2}\right]}<\frac{1}{k-1} \\
& \sqrt{1.2\left[(0.278883-0.266954)^{2}+(0.029179-0.009170)^{2}\right]} \geq \frac{1}{2-1} \\
& \sqrt{0.000271}=0.01646<1
\end{aligned}
$$

Now, as the VIKOR index values of both customers 1 and 7 are smaller than this value, the lowest VIKOR index value, that is, the first customer is ranked the first and is preferred to the customer 7 . The rest of customers were ranked accordingly as it is shown in Table (12).

Table 12: The final ranking of options

\begin{tabular}{|c|c|}
\hline Intended customer & Final ranking \\
\hline 1 & 1 \\
\hline 7 & 2 \\
\hline 9 & 3 \\
\hline $6 \approx 3 \approx 16$ & 4 \\
\hline 14 & 5 \\
\hline 2 & 6 \\
\hline 8 & 7 \\
\hline 18 & 8 \\
\hline 12 & 9 \\
\hline 20 & 10 \\
\hline 5 & 11 \\
\hline 15 & 12 \\
\hline 4 & 13 \\
\hline 13 & 14 \\
\hline 10 & 15 \\
\hline 11 & 16 \\
\hline 17 & 17 \\
\hline 19 & 18 \\
\hline
\end{tabular}

The data are based on the facilities provided to customers who have received facilities in the past. After the final ranking of the customers scientifically, the researcher referred to Tejarat Bank and obtained information on the status of the customers whose data were used in this research. It was qualitatively found that customers 1, 7, and 9 with top ranks in the scientific rankings had excellent status in terms of repayment of the received facilities to Tejarat Bank. Accordingly, the customers in the middle ranks of the table had normal status and it was found that the customers in the final ranks had poor status in the repayment of their received facilities to the Tejarat Bank. This result suggests that the method of ranking based on Rough VIKOR can be applied to all customers referred to bank from this time onwards to receive the banking facilities and the customers who are in poor status should be rejected in order to prevent financial and credit costs and outsourcing costs of follow-ups, imposed on banks.

\section{Conclusion and recommendations for future studies}

In this study, the key and effective factors were identified. These factors included location for use of granted facilities and type of use of facilities in that region, history of activity, and level of customer capital, type of collateral, having previous liabilities, good reputation of the applicant, and estimating the rate of return. Then, the weights of the key and important factors were obtained. It was concluded that estimating the rate of return was ranked in terms of importance and the history of activity was ranked the second. It should be noted here that the first and second ranks had about $80 \%$ importance among the factors, indicating very high importance of these two factors in terms of Pareto 20-80 strategy. Finally, Rough VIKOR method was applied and the customers who had received loans, facilities and credits from Tejarat Bank in the past were ranked. According to the analysis, the results show that the Rough VIKOR-based ranking method can be applied to all customers who refer to bank since this time onwards to receive facilities and the customers who are in poor status should be rejected in order to prevent financial and credit costs and outsourcing costs of follow-ups, imposed on banks. 
In this section, recommendations are provided for future researchers in this field and development of this research. These recommendations include:

- This study provided a new approach for Tejarat Bank and other researchers can investigate the effectiveness of this method in the intended bank after implementing this new method in bank and achieving the quantitative goals of bank and investigate this method further.

- Researchers can also calculate the rate of reduction in overhead costs incurred by providing facilities to inappropriate individuals on the bank, using the economic and financial models after applying this method in the intended bank and transform the efficiency of this method into comprehensible numbers.

- This research was conducted on real customers. Other researchers can take steps towards more effective implementation of this research for all customers in future studies by classifying customers according to the banking system classification and applying this method in each of the classifications.

\section{References}

[1] Castro, V. (2013). Macroeconomic determinants of the credit risk in the banking system: The case of the GIPSI. Economic Modeling, 31, 672-683.

[2] Che, Z., Wang, H. S., \& Chuang, C. L. (2010). A fuzzy AHP and DEA approach for making bank loan decisions for small and medium enterprises in Taiwan. Expert Systems with Applications, 37(10), 7189-7199.

[3] Da Silva, M. S., \& Divino, J. A. (2013). The role of banking regulation in an economy under credit risk and liquidity shock. The North American Journal of Economics and Finance, 26, 266-281.

[4] Forman, E., \& Peniwati, K. (1998). Aggregating individual judgments and priorities with the analytic hierarchy process. European journal of operational research, 108(1), 165-169.

[5] Ghenimi, A., Chaibi, H., \& Omri, M. A. B. (2017). The effects of liquidity risk and credit risk on bank stability: Evidence from the MENA region. Borsa Istanbul Review.

[6] Hsiao, B., Chern, C. C., Chiu, Y. H., \& Chiu, C. R. (2011). Using fuzzy super-efficiency slack-based measure data envelopment analysis to evaluate Taiwan's commercial bank efficiency. Expert Systems with Applications, 38(8), 9147-9156.

[7] Huang, J. J., Tzeng, G. H., \& Liu, H. H. (2009). A revised VIKOR model for multiple criteria decision making - the perspective of regret theory. In: Shi, Y. et al (Eds.) Cutting-Edge Research Topics on Multiple Criteria Decision Making. Springer, Berlin Heidelberg, 761768.

[8] Imbierowicz, B., \& Rauch, C. (2014). The relationship between liquidity risk and credit risk in banks. Journal of Banking \& Finance, $40,242-256$.

[9] Manab, N. A., Theng, N. Y., \& Md-Rus, R. (2015). The Determinants of Credit Risk in Malaysia. Procedia-Social and Behavioral Sciences, 172, 301-308.

[10] M.K. Sayadi, M. Heydari, K. Shahanaghi. (2009). Extension of VIKOR method for decision making problem with interval numbers, Appl. Math. Model. 33 (5) 2257-2262.

[11] Turan, H. (2016). The Weighting of Factors Affecting Credit Risk in Banking. Procedia economics and finance, $38,49-53$.

[12] Odeh, O., Koduru, P., Featherstone, A., Das, S., \& Welch, S. M. (2011). A multi-objective approach for the prediction of loan defaults. Expert Systems with Applications, 38(7), 8850-8857.

[13] Pawlak, Z., Inuiguchi, M., Hirano, S., \& Tsumoto, S. (2003). Rough Set Theory and Granular Computing. English: Springer-Verlag Berlin Heidelberg.

[14] Rao, V. (2012). Decision Making in Manufacturing Environment Using Graph Theory and Fuzzy Multiple Attribute Decision Making Methods, vol. 2, Springer.

[15] Zhu, G. N., Hu, J., Qi, J., Gu, C. C., \& Peng, Y. H. (2015). An integrated AHP and VIKOR for design concept evaluation based on rough number. Advanced Engineering Informatics, 29(3), 408-418.

[16] Zhou, J., \& Tian, J. (2008). Optimal selection of FGD technology using GA-based roughsets theory and VIKOR. Paper presented at the International Conference on Automation and Logistics, Qingdao, China September 2008.

[17] Azadi Mogaddam Arani, A; Amin Naseri, MR; Ghodsipour, SH; (2004, July). Bank Loan Evaluation Model Using AHP Technique. International Conference on Industrial Engineering (p. 16). Tehran: Amir Kabir University of Technology.

[18] Asgharpour, MJ (2011). Multiple criterion decision making. Tehran: Tehran University Publications.

[19] Amiri, Z; Amiri, M (2015). Technical and Economic Evaluation of Loan Applicant Projects Using Fuzzy Analytic Network (FANP) Technique. Journal of Management Development \& Evolution, 11-25.

[20] Aghaei, T (2009). New banking knowledge for the scientific advancement of the branch staff. Tehran.

[21] Khaki, Gh (2008). Research method with a thesis writing approach. Tehran: Derayat Publications.

[22] Khamseh, K; Haj Karimi, AA; Akhavan, M (2007). Providing an expert (intelligent) decision-making model for granting facilities for customers. The First World Bank E-Banking Conference.

[23] Zabihi, M; Dariush, A; Taheri, M; Taheri, A; (2012). Identifying and prioritizing the criteria for granting facilities using the FUZZY AHP technique. First National Conference on Strategies for Promoting Management, Accounting and Industrial Engineering Issues in Organizations, p. 17.

[24] Shahgholian, K; Yaghoubi, NM; Kharkuei, AH; (2011, September). Providing a Decision Model for Granting Banking Facilities Using Fuzzy Decision Making. 14th Iranian Student Conference on Electrical Engineering (p. 6). Kermanshah: Kermanshah University of Technology.

[25] Karimi, Z; Asadi Gorji, H; Gilak Hakimabadi, MT; Asadi, N; (2015). Factors Affecting Credit Risk of Commercial Bank Customers (Case Study: Tejarat Bank of Neka - Mazandaran Province). Bimonthly Journal of Financial and Monetary Economics (Former Knowledge and Development), 205-234.

[26] Kighobadi, AR; Khodami, V (2013). Data mining of financial statements for granting financial facilities. Financial Accounting and Auditing Research, 179-211.

[27] Nagadeh, H; Babaei, A; Abtahi, SAR (2013). Providing a methodology for selecting the preferred person to grant loan facilities. Second National Conference on Industrial and Systems Engineering (p. 8). Isfahan: Islamic Azad University, Najaf Abad Branch, Department of Industrial Engineering. 